1 Fundação Oswaldo Cruz (Fiocruz), Escola Naciona de Saúde Pública Sergio Arouca (Ensp) - Rio de Janeiro (RJ), Brasil.

${ }^{2}$ Fundação Oswaldo Cruz (Fiocruz), Escola Naciona de Saúde Pública Sergio Arouca (Ensp) - Rio de Janeiro (RJ), Brasil.

3 Fundação Oswaldo Cruz (Fiocruz), Escola Nacional de Saúde Pública Sergio Arouca (Ensp) - Rio de Janeiro (RJ), Brasil.

\section{Democracia, direitos humanos, desigualdade e saúde: que caminhos trilhamos?}

\author{
Ary Carvalho de Miranda1, Hermano Albuquerque de Castro², Lucia Regina Florentino Souto ${ }^{3}$
}

DOI: $10.1590 / 0103-110420185300$

A CRISE DO CAPITALISMO DE 1929, a partir do crash da bolsa de Nova York, impactou praticamente todo o mundo, com falências de empresas, desemprego e grave impacto social. Um de seus desfechos foi a tragédia da II Grande Guerra Mundial, que deixou 50 milhões de mortos, outros milhões de mutilados e dezenas de países destruídos. Foi a receita do capital para suas próprias contradições.

A crise disseminada no mundo hoje tem sido considerada por especialistas de várias áreas do conhecimento como a mais grave desde 1929. Em 2008, de repente, evaporaram aproximadamente US\$ 40 trilhões do patrimônio global e US\$ 14 trilhões de riquezas das famílias. Quatro milhões de pessoas perderam os empregos; e, de 2008 a 2011, a cada 3 meses, 250 mil famílias tiveram que sair de suas casas apenas nos EUA'. A crise ganhou a Europa e o resto do mundo. Uma de suas marcas mais cruéis é o aumento da desigualdade em um mundo já desigual. Hoje, em todo o planeta, 800 milhões de pessoas têm fome em um cenário em que, entre 1988 e 2011, a renda dos $10 \%$ mais pobres aumentou US\$ 65,00, enquanto a do $1 \%$ mais rico aumentou US\$11.800,00, ou seja, 182 vezes $^{2}$.

Essa concentração de riqueza não se deve apenas à financeirização desregulamentada imposta pelas forças hegemônicas do neoliberalismo, mas sua participação é dominante. Enquanto o Produto Interno Bruto (PIB) mundial tem crescido entre $1 \%$ e 2,5\%, as aplicações financeiras rendem acima de $5 \%$. Cria-se, assim, uma dinâmica em que a capacidade produtiva, vinculada às necessidades sociais, é transformada em patrimônio financeiro, apropriado por grupos transnacionais monopolizados. Em outras palavras, dinheiro produzindo dinheiro sem qualquer compromisso social, de tal ordem que apenas nos EUA, em 2008, o volume de crédito era $365 \%$ do PIB. Foi o estouro da bolha que contraditoriamente fez o congresso nacional daquele país aprovar, em outubro de 2018, US $\$ 800$ bilhões para salvar Wall Street'.

Os efeitos globais não demoraram. No Brasil, um país sem políticas universais de proteção social, o impacto econômico atinge principalmente as populações mais necessitadas. O golpe jurídico-parlamentar-midiático de 2016 escancarou as portas para o aumento da desigualdade. A aprovação da PEC 95, que congela por 20 anos os investimentos do Estado, e a aprovação da Reforma Trabalhista, que refina os instrumentos institucionais para o aumento da exploração sobre os trabalhadores, são componentes desse processo que aponta para um cenário ainda mais preocupante. Aumentou o desemprego e fez cair a renda, com rápidas consequências sobre as condições sociais, expressas na escalada da violência, no retorno do País ao mapa da fome, na volta do sarampo e no crescimento da taxa de mortalidade infantil, apenas para citar alguns componentes da situação atual. Isto é, entramos em um ponto de bifurcação entre 
civilização e barbárie. Uma nação solidária, que enfrente suas desigualdades, não pode jamais estar a serviço do $1 \%$ mais rico.

São tempos difíceis que nos matam 60 mil vezes no ano, a maioria jovem, pobre e negra. Somos atacados por sermos mulheres, por sermos LGBTI+ e por defendermos os direitos humanos. Batemos todos os recordes dos crimes contra setores específicos da população. A violência brasileira é superior a muitos lugares em guerra.

Todo esse retrocesso atingiu também o sistema de saúde em todos os seus níveis de atenção. Inicia-se com a mudança na Política Nacional de Atenção em Básica (PNAB), em que se retira a padronização do número de Agentes Comunitários de Saúde (ACS) por equipe da Estratégia Saúde da Família (ESF) com a finalidade de reduzir os custos no setor; assim como a reformulação da PNAB, em 2017, que colocou em xeque a integralidade, o trabalho dos ACS e importantes avanços da $\mathrm{ESF}^{3}$.

O Sistema Único de Saúde (SUS) tem sofrido desde a sua criação um subfinanciamento crônico, agora agravado, e vive um desabastecimento de insumos de saúde sem precedentes que condena o País a um colapso de saúde, sanitário e social. Para ilustrar tal fato, caso a PEC 95 estivesse em vigor entre 2003 e 2015 , a União teria gasto $42 \%$ a menos ( 257 bilhões) com ações e serviços públicos de saúde. Os recursos públicos investidos na saúde pelo governo federal, no ano pós-golpe, em 2017, foram de apenas $\mathrm{R} \$ 101,134$ bilhões com um aumento de $2,23 \%$ em relação a 2016, quando a inflação do ano foi de 2,95\%. O que é alardeado pelas autoridades como economia, na verdade, representa a subtração de direitos na saúde pública 4 .

São necessários investimentos públicos que possam superar as desigualdades sociais com severo impacto na saúde. Por exemplo, a expectativa de vida ao nascer entre quem vive na região mais rica e quem vive na mais pobre do País chega a variar 26 anos. A mortalidade infantil em áreas das regiões Norte e Nordeste é sempre maior do que a média nacional - e com tendência de aumento com a retirada das políticas sociais. Houve uma desaceleração na política de saneamento básico, o que contribuiu para o retorno das emergências sanitárias com a volta de doenças, como foi o caso também da febre amarela. Isso sem considerar os impactos socioambientais de um modelo de desenvolvimento que privilegia a mineração e o agronegócio, fazendo o País consumir um milhão de toneladas de agrotóxicos ao ano e protagonizar o maior crime ambiental do mundo decorrente da mineração, como foi o caso do rompimento da barragem da Samarco, em Mariana (MG).

O Programa Mais Médicos ajudou a enfrentar uma carência histórica de médicos na atenção básica, em diferentes municípios do País, mas ainda ficou longe de resolver a questão da formação médica e de outros profissionais de saúde que atendam a população rural e urbana que ficam distantes dos grandes centros do Brasil. O Estado precisa retomar o papel de regulação e de formação de quadros para o SUS, levando aos locais mais precarizados as ações de saúde. Uma das propostas em andamento no País é o fomento à uma política aos planos de saúde para os pobres, o que precariza ainda mais o SUS e acentua a mercantilização do sistema de saúde brasileiro. É fundamental a resistência para encerrar o ciclo da privatização e do subfinanciamento. A população necessita da atenção integral à saúde, que, para isso, precisa contar com aumento dos recursos assistenciais. É importante que avancemos na construção de uma política para o País que torne a atenção primária forte, qualificada, integral, longitudinal e resolutiva, com a universalização da cobertura em todos os níveis de atenção 5 .

A possibilidade de conter o retrocesso em curso só será possível com a ampla participação de todos os setores da sociedade, comprometidos com uma outra concepção de mundo, em que prevaleçam os respeito às diversas formas de expressão da vida, como raça, gênero e sexualidade, assim como com a emancipação dos trabalhadores de todas as formas de opressão, 
em um mundo onde o espírito da solidariedade suplante a violência e a exclusão em curso. A construção do SUS só foi possível devido à ampla participação social dos profissionais, entidades e instituições da saúde, dos sindicatos dos trabalhadores da cidade e do campo, dos diversos conselhos profissionais, do movimento das mulheres, das associações de moradores, dos quilombolas e de uma série de outros movimentos em um vigoroso processo democrático. No resgate desse processo, está a esperança da contenção da acentuação do grave cenário que já está em curso.

Neste momento, é fundamental fortalecer nossa Constituição de 1988, a soberania nacional e os direitos universais!

Ary Carvalho de Miranda

Fundação Oswaldo Cruz (Fiocruz) - Escola Nacional de Saúde Pública Sergio Arouca (Ensp) Rio de Janeiro (RJ), Brasil.

Hermano Albuquerque de Castro

Fundação Oswaldo Cruz (Fiocruz) - Escola Nacional de Saúde Pública Sergio Arouca (Ensp) Rio de Janeiro (RJ), Brasil.

Lucia Regina Florentino Souto

Fundação Oswaldo Cruz (Fiocruz) - Escola Nacional de Saúde Pública Sergio Arouca (Ensp) Rio de Janeiro (RJ), Brasil.

\section{Referências}

1. Varoufakis Y. O Minotauro Global. A Verdadeira Origem da Crise Financeira e o Futuro da Economia Global. São Paulo: Editora Autonomia Literária; 2016.

2. Dowbor L. A Era do Capital Improdutivo. A nova arquitetura do poder, sob dominação financeira, sequestro da democracia e destruição do planeta. São Paulo: Editoras Outras Palavras e Autonomia Literária; 2017.

3. Morosini MVGC, Fonseca AF. Revisão da Política Nacional de Atenção Básica numa hora dessas? Cad
Saúde Pública. 2017; 33(1):1-4.

4. Vieira FS, Benevides RPS. Os impactos do novo regime fiscal para o financiamento do Sistema Único de Saúde e para a efetivação do direito à saúde no Brasil. Brasília, DF: IPEA; 2016.

5. Fontenelle LF. Mudanças recentes na Política Nacional de Atenção Básica: uma análise crítica. Rev bras med fam comunidade. 2012 jan-mar; 7(22):5-9. 